\title{
Correction to: Immunosuppression Drug Therapy in Lung Transplantation for Cystic Fibrosis
}

\author{
Pamela Burcham $^{1}$ - Lisa Sarzynski, ${ }^{2,5}$ Sabrina Khalfoun ${ }^{2,5} \cdot$ Kimberly J. Novak ${ }^{5,8}$. \\ Julie C. Miller ${ }^{8}$ Dmitry Tumin ${ }^{2,6,7} \cdot$ Don Hayes $\mathbf{J r}^{2,3,4,5,7}$
}

Published online: 9 March 2018

(C) Springer International Publishing AG, part of Springer Nature 2018

Correction to: Pediatr Drugs (2017) 19:339-346

https://doi.org/10.1007/s40272-017-0236-2

In the print publication the name of the seventh author was incorrectly published.

Page 339, author listing: The name of the seventh author, which previously read:

"Don Hayes"

should read

"Don Hayes Jr"

The original article can be found online at https://doi.org/10.1007/ s40272-017-0236-2.

Don Hayes Jr

hayes.705@osu.edu

1 Department of Pharmacy, The Ohio State University, Columbus, OH, USA

2 Department of Pediatrics, The Ohio State University, 700 Children's Drive, Columbus, OH 43205, USA

3 Department of Internal Medicine, The Ohio State University, Columbus, OH, USA

4 Department of Surgery, The Ohio State University, Columbus, OH, USA

5 Section of Pulmonary Medicine, Nationwide Children's Hospital, Columbus, OH, USA

6 Department of Anesthesiology and Pain Medicine, Nationwide Children's Hospital, Columbus, OH, USA

7 Center for Epidemiology of Organ Failure and Transplantation, Nationwide Children's Hospital, Columbus, $\mathrm{OH}$, USA

8 Department of Pharmacy, Nationwide Children's Hospital, Columbus, OH, USA 